\title{
混合モード円形き裂の一般解と炎の応用について*
}

\author{
西岡 俊 久*1, 周 广 勤*2, 藤 本 岳 洋*3
}

\section{On the General Solutions for Mixed-Mode Penny-Ohaped Crack and Their Applications}

\author{
Toshihisa NISHIOKA*4, Guangqin ZHOU and Takehiro FUJIMOTO \\ ${ }^{* 4}$ Faculty of Maritime Sciences, Kobe University,
5-1-1 Fukaeminamimachi, Higashinada-ku, Kobe-shi, Hyogo, 658-0022 Japan
}

\begin{abstract}
The general solutions for a penny-shaped crack in an infinite solid, subjected to arbitrary tractions on the crack surfaces were derived. The applicability was demonstrated deriving the closed-form solutions for a penny-shaped crack subjected to the lower-order loading such as constant tension, shear, bending, and torsion. Furthermore, we consider a circular crack subjected to cubic-order normal stresses. It is shown that the stress intensity factor distribution derived from the general solution exactly agree with the analytical solutions derived by Shah-Kobayashi.
\end{abstract}

Key Words: Fracture Mechanics, Stress Intensity Factor, Penny-shaped Crack, Residual Stress, Mixed-Mode, VNA Solution

\section{1. 緒言}

破壊力学は現在, 様々な機器・構造物の安全設計に 盛んに用いられ，その有効性は多くの分野で認識され ている. 一般に, 三次元構造物中の実際のき裂は円形 き裂，あるいはだ円き裂で近似されることが多い。こ のため, 三次元円形き裂の研究は多くなされてきた.

任意の次数の多項式で表される垂直及びせん断荷重 を受けるだ円き裂一般解の導出の試みが, VijayaKumar·Athri ${ }^{(1)}$ によってなされた. その後完全な 解の導出が Nishioka·Atturi ${ }^{(2)(3)}$ によって行われた. この 解は簡便のため, VNA（VijayaKumar-Nishioka·Athri)解と 呼ばれている ${ }^{(4)}$. WA 解は一般だ円積分, 任意のポテ ンシャル関数の任意次数の微分などを含め, 極めて任

\footnotetext{
* 原稿受付 2005 年 7 月 7 日.

*1 フェロー, 神戸大学海事科学部( - 658-0022 神戸市東灘区 深江.南町 5-1-1).

*2 学生員, 神戸大学大学院自然科学研究科.

*3 正員, 神戸大学海事科学部.

E-mail : nishioka @ maritime.kobe- u.ac.jp
}

意のき裂面の荷重について有用である.

だ円き裂の一般解はあくまでもだ円き裂のものであ る. 円形き裂の場合, き裂のアスペクト比 $k=a_{2} / a_{1}$ 及び関連比 $k^{\prime}=1-k^{2}$ はそれぞれ $k=1, k^{\prime}=0$ とな り, これらの值をだ円き裂の一般解に用いると, 分母 がゼロとなる項が各所に現れる. 円形き裂の解は工学 的に極めて重要であるので, 上記の数学的困難を克服 し，一般解を導出する意義は非常に大きいと考えられ る. 本研究では WNA 解を基に任意の次数の多項式で表 される荷重が表面に作用する無限体中の円形き裂の一 般解を導出した. この円形き裂の一般解は, 任意の点 における変位·応力分布を導出可能であり, さらには 破壊力学パラメータを評価できる.この解を用いて低 次の引っ張り, せん断, 曲げ及びねじり荷重分布に対 して，この円形き裂の一般解によって容易に閉じた解 が導けることを示し，これらの解が他の文献(6) の解 と完全に一致することを示す，そして，本論文におい て, 円形き裂の一般解を用いて円形き裂面における直 線的に変化するせん断荷重分布に対して, 導出した各 モードの応力拡大係数を示した. 
さらにここの円形き裂一般解と開発したプログラム の有効性を調べるため, 解析例として, き裂面に 2 次 及び 3 次の荷重分布を受ける無限弾性体内に存在する 円形き裂の場合を解析した. この数值解析解の信頼性 を調べるために Shah·Kobayashi ${ }^{(7)}$ による解析解と比較 して，両者が完全に一致することにより，この円形き 裂の一般解の妥当性を検証した.

\section{2. 無限体中単数円形き裂の一般解}

\section{1 調和応力関数}

図 1 に示すような無限体中の半径 $a$ の円形き裂を考 える. 直交デカルト座標 $\left(x_{1}, x_{2}, x_{3}\right)$ の原点を円形き裂 の中心にとると, 円形き裂縁は次式で表される.

$$
\left(x_{1} / a\right)^{2}+\left(x_{2} / a\right)^{2}=1
$$

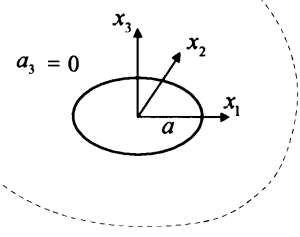

Fig 1 Apenny-shapedcrack in an infinite solid

円形き裂の解析においては, 図 2 に示すだ円体ボイ ドから $a_{3}=0, a_{1}=a_{2}=a$ とすることによって容易 に円形き裂のモデルができるので，だ円体座標を用い たほうが便利である.

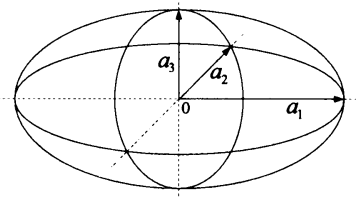

Fig 2 An ellipsoidal Void which expresses axis length

だ円体座標 $\xi_{\alpha}$ は次式で与えられる 3 次方程式の根 として与えられる.

$$
\omega(s)=1-\left(\frac{x_{1}^{2}}{a^{2}+s}\right)-\left(\frac{x_{2}^{2}}{a^{2}+s}\right)-\left(\frac{x_{3}^{2}}{s}\right)=0
$$

したがって，円形き裂の解析においては，だ円体座 標 $\xi_{\alpha}(\alpha=1,2,3)$ の值は次式で簡単に計算できる.

$$
\begin{aligned}
& \xi_{1}=-a^{2} \\
& \xi_{2}=\frac{1}{2}\left[r^{2}-a^{2}-\sqrt{\left(r^{2}-a^{2}\right)^{2}+4 a^{2} x_{3}^{2}}\right] \\
& \xi_{3}=\frac{1}{2}\left[r^{2}-a^{2}+\sqrt{\left(r^{2}-a^{2}\right)^{2}+4 a^{2} x_{3}^{2}}\right] \\
& \text { ここで, } \quad r^{2}=x_{1}^{2}+x_{2}^{2}+x_{3}^{2} \\
& -a^{2}=\xi_{1} \leq \xi_{2} \leq 0 \leq \xi_{3}<\infty \quad ;\left(x_{3}=0\right)
\end{aligned}
$$

このだ円体座標を用いると $x_{3}=0$ 平面で, き裂内 部は $\xi_{3}=0$, き裂外部は $\xi_{2}=0$ ，そしてき裂縁は $\xi_{2}=\xi_{3}=0$ で表すことができる. 式(2)は書き換える と次式のようになる.

$$
\omega(s)=P(s) / Q(s)
$$

ここに

$$
\begin{gathered}
P(s)=\left(s-\xi_{1}\right)\left(s-\xi_{2}\right)\left(s-\xi_{3}\right) \\
Q(s)=s\left(s+a^{2}\right)\left(s+a^{2}\right)
\end{gathered}
$$

変位で表した弾性体の基礎方程式は

$$
u_{\beta, \beta \alpha}+(1-2 v) u_{\beta, \beta \beta}=0, \quad(\alpha, \beta=1,2,3)
$$

ここにvはポアソン比を表す。また（ $)_{\alpha}$ は $\partial() / \partial x_{\alpha}$ を意味する.

式(6) は三つの調和応力関数 $f_{\alpha}(\alpha=1,2,3)$ によって 満足される.

$$
f_{\alpha}=\sum_{k} \sum_{l} C_{\alpha, k, l} F_{k l}
$$

ここに $C_{\alpha, k, l}$ は未定係数でコンマは添え字の区別のた め便宜上用いられ， $F_{k l}$ はポテンシャル関数である(12).

$$
F_{k l}=\int_{\xi_{3}}^{\infty} \partial_{1}^{k_{1}} \partial_{2}^{l_{1}} \partial_{3}^{m_{1}} \omega(s)^{k+l+1} \frac{d s}{\sqrt{Q(s)}}
$$

$$
\text { ここに } \quad k_{1}=k ; l_{1}=l ; m_{1}=0
$$

ここに $\partial_{\alpha}^{j}$ は $x_{\alpha}$ に関する $j$ 階の偏微分を表わす.

式(7)をマトリックス表示すると，下の式で表され る.

$$
f_{\alpha}=\{F\}^{T}\{C\}
$$


変位 $u_{i}$ および応力 $\sigma_{i j}$ は調和応力関数 $f_{\alpha}$ を用いて 次のように表すことができる.

$$
\begin{aligned}
& u_{1}=(1-2 v)\left(f_{1,3}+f_{3,1}\right)-(3-4 v) f_{1,3}+x_{3}(\nabla \cdot \hat{f})_{, 1} \\
& u_{2}=(1-2 v)\left(f_{2,3}+f_{3,2}\right)-(3-4 v) f_{2,3}+x_{3}(\nabla \cdot \hat{f})_{, 2} \\
& u_{3}=(1-2 v)\left(f_{1,1}+f_{2,2}\right)-2(1-v) f_{3,3}+x_{3}(\nabla \cdot \hat{f})_{, 3} \\
& \text { また, } \\
& \sigma_{11}=2 \mu\left[f_{3,11}+2 v f_{3,22}-2 f_{1,31}-2 v f_{2,32}+x_{3}(\nabla \cdot \hat{f})_{, 11}\right] \\
& \sigma_{22}=2 \mu\left[f_{3,22}+2 v f_{3,11}-2 f_{2,32}-2 v f_{1,31}+x_{3}(\nabla \cdot \hat{f})_{, 22}\right] \\
& \sigma_{12}=2 \mu\left[(1-2 v) f_{3,12}-(1-v)\left(f_{1,23}+f_{2,13}\right)_{3}+x_{3}(\nabla \cdot \hat{f})_{, 12}\right] \\
& \sigma_{33}=2 \mu\left[\left(f_{3,11}+f_{3,22}\right)+x_{3}(\nabla \cdot \hat{f})_{, 33}\right] \\
& \sigma_{31}=2 \mu\left[f_{1,11}-(1-v) f_{1,22}+v f_{2,21}+x_{3}(\nabla \cdot \hat{f})_{13}\right] \\
& \sigma_{32}=2 \mu\left[f_{2,22}-(1-v) f_{2,11}+v f_{1,12}+x_{3}(\nabla \cdot \hat{f})_{, 23}\right] \\
& こ こ て ゙, \quad \nabla \cdot \hat{f}=f_{1,1}+\dot{f}_{2,2}+f_{3,3}
\end{aligned}
$$

$\mu$ は横弾性係数を表す。

\section{2 き翌面に作用する荷重分布}

無限に広がる弹性体内に存在する円形き裂の面上に 作用する任意の分布荷重 $\sigma_{3 \alpha}^{(0)}(\alpha=1,2,3)$ は次式のよ うに級数展開できるものとする.

$$
\sigma_{3 \alpha}^{(0)}=\sum_{i=0}^{1} \sum_{j=0}^{1} \sum_{m=0}^{M} \sum_{n=0}^{m} A_{\alpha, m-n, n}^{(i, j)} x_{1}^{2 m-2 n+i} x_{2}^{2 n+j}
$$

上式をマトリックス表示すると，下の式で表される.

$$
\sigma_{3 \alpha}^{(0)}=\{L\}^{T}\{A\}
$$

$A_{\alpha, m-n, n}^{(i, j)}$ は未定係数であり, $(i, j)$ はそれぞれ $x_{1}, x_{2}$ 軸に対する荷重の対称性を示している添字である. $M$ は任意の整数で, 式(13)に対する完全多項式の次 数 $M_{c}$ との関倸は $M_{c}=2 M+1$ であり, また級数の項 数と $N=(M+1)(2 M+3)$ の関係がある. また, 不完全 多項式の次数と項数は $M$ ばかりでなく, $(i, j)$ にも依 存する. そして, $(i, j)$ の対称性を考慮して式(7)を書 き直すと以下のようになる.

$$
f_{\alpha}=\sum_{i=0}^{1} \sum_{j=0}^{1} \sum_{k=0}^{M} \sum_{l=0}^{k} C_{\alpha, k-l, l}^{(i, j)} F_{2 k-2 l+i, 2 l+j}
$$

このとき，式(7)にある $k, l$ はそれぞれ $(2 k-2 l+i)$ ， $(2 l+j)$ で置換された. き裂面上 $\left(x_{3}=0\right)$ の境界条件 は, $\sigma_{3 \alpha}^{(0)}=\sigma_{3 \alpha}(\alpha=1,2,3)$ であるため, 式(11)より調和 応力関数を用いて次の式が得られる.

$$
\begin{gathered}
\sigma_{3 \alpha}^{(0)}=2 \mu\left[(1-v)\left(f_{\alpha, 11}+f_{\alpha, 22}\right)+v\left(f_{1,1 \alpha}+f_{2,2 \alpha}\right)\right] ;(\alpha=1,2) \\
\sigma_{33}^{(0)}=2 \mu\left(f_{3,11}+f_{3,22}\right)
\end{gathered}
$$

ここで調和関数のもつ以下の関倸が用いられる.

$$
f_{\alpha, 33}=-\left(f_{\alpha, 11}+f_{\alpha, 22}\right) ;(\alpha=1,2,3)
$$

式(13) と式(15)を式(16), (17)に代入し, 多項式の次 数を比較することにより, 次の代数方程式を得ること ができる.モードI 型に対しては,

$$
\begin{aligned}
& A_{3, m-n, n}^{(i, j)}=2 \mu \frac{(-1)^{m+i+j}}{(2 m-2 n+i) !(2 n+j) !} \sum_{k=m}^{M} \sum_{l=0}^{k}(-1)^{k} \\
& {\left[I_{1}^{(i, j)} J_{L_{L_{1}+1}, L_{2}, 0}(0)+I_{2}^{(i, j)} J_{L_{1}, L_{2+1}, 0}(0)\right] \cdot C_{3, k-l, l}^{(i, j)}} \\
& \text { ここで, }\left(\begin{array}{l}
i=0,1, \quad j=0,1, \quad m=0,1, \cdots, M \\
n=0,1, \cdots, m
\end{array}\right) \\
& L_{1}=m-n+k-l+i, \quad L_{2}=n+l+j \text { となる } .
\end{aligned}
$$

$$
\begin{gathered}
A_{\alpha, m-n, n}^{(i, j)}=2 \mu \frac{(-1)^{m+i+j}}{(2 m-2 n+i) !(2 n+j) !}\left\langle\sum_{k=m}^{M} \sum_{l=0}^{k}(-1)^{k}\right. \\
\left\{(1-v)\left[I_{1}^{(i, j)} J_{L_{1}+1, L_{2}, 0}(0)+I_{2}^{(i, j)} J_{L_{1}, L_{2}+1,0}(0)\right]\right. \\
\left.+v I_{1}^{(i, j)} J_{L_{1}+\delta_{1 a}, L_{2}+\delta_{2}, 0}(0)\right\} \cdot C_{\alpha, k-l, l}^{(i, j)} \\
+(-1)^{k+1-i-j-j} \sum_{k=m_{2} l=0}^{M_{2}} \sum^{k} v I_{12}^{(1-i, 1-j)} J_{L_{1}+1-i, L_{2}+1-j, 0}(0) \\
\left.\cdot C_{\beta, k-l, l}^{(1-i, 1-j)}\right\rangle
\end{gathered}
$$

$$
\begin{gathered}
(i=0,1, \quad j=0,1, \quad \alpha=1,2, \quad \beta=3-\alpha, \\
M_{1}=M-\delta_{i j} \delta_{i 1}, \quad M_{2}=M-\delta_{i j}, \\
m_{2}=m+(-1)^{1+i} \delta_{i j}, \quad m=0,1, \cdots, M_{1}, \\
n=0,1, \cdots, m) \text { となる. }
\end{gathered}
$$

また,このとき以下の関係が成り立つことになる.

$$
\begin{gathered}
I_{\alpha}^{(i, j)}=\frac{(2 k+i+j+1) !}{(k-m) !} \frac{\left(2 L_{1}+2 \delta_{1 \alpha}\right) !}{\left(L_{1}+\delta_{1 \alpha}\right) !} \frac{\left(2 L_{2}+2 \delta_{2 \alpha}\right) !}{\left(L_{2}+\delta_{2 \alpha}\right) !} \\
I_{12}^{(1-i, 1-j)}=\frac{(2 k+3-i-j) !}{(k-m+1-i-j) !} \frac{\left(2 L_{1}+2-2 i\right) !\left(2 L_{2}+2-2 j\right) !}{\left(L_{1}+1-i\right) !} \frac{\left(L_{2}+1-j\right) !}{}
\end{gathered}
$$


ここで, $\delta_{i j}$ はクロネッカーのデルタである. 式(19), (20)をマ リックスで表示すると,

$$
\begin{gathered}
\underbrace{\left\{A_{3, m-n, n}^{(i, j)}\right.}_{N \times 1}\}=\underbrace{\left[B_{33}\right]}_{N \times N} \underbrace{\left\{C_{3, m}^{(i, j)}\right.}_{N \times 1}\} \\
\underbrace{\left(\begin{array}{l}
A_{1, m-n, n}^{(i, j)} \\
A_{2, m-n, n}^{(i, j)}
\end{array}\right)}_{2 N \times 1}=\underbrace{\left[\begin{array}{ll}
{\left[B_{11}\right]} & {\left[B_{12}\right]} \\
{\left[B_{21}\right]} & {\left[B_{22}\right]}
\end{array}\right]}_{2 N \times 2 N} \underbrace{\left(\begin{array}{l}
C_{1, k-l, l}^{(i, j)} \\
C_{2, k-l, l}^{(i, j)}
\end{array}\right)}_{2 N \times 1}
\end{gathered}
$$

となる. ここに, $N$ は各応力成分 $\sigma_{3 \alpha}^{(0)}(\alpha=1,2,3)$ に 対し, 式(13)で用いられた多項式の項数を示す.

また, 式(19), (20)に示された $J_{p-q, q-r, r}$ は一般だ円積 分と呼ばれ, 次式で定義される( ${ }^{(3)}$.

$$
J_{p-q, q-r, r}\left(\xi_{3}\right)=\int_{\xi_{3}}^{\infty} \frac{d s}{\left(s+a_{1}^{2}\right)^{p-q}\left(s+a_{2}^{2}\right)^{q-r}\left(s+a_{3}^{2}\right)^{r} \sqrt{Q(s)}}
$$

ここで， $a_{1}, a_{2}, a_{3}$ は図 2 に示すようにそれぞれだ円 体の三つの軸長さを表す．円形き裂においては $a_{1}=a_{2}=a ， a_{3}=0$ が用いられる.

式(25)はヤコビのだ円関数 (のを用いて表すと, 次の 式に書き換えることができる( ${ }^{(3)}$.

$$
\begin{aligned}
& J_{p-q, q-r, r}=\frac{2}{a^{2 p+1}} \int_{0}^{u_{1}}\left(s n^{2 p} u\right)\left(n d^{2 q-2 r}\right)\left(n c^{2 r} u\right) d u \\
& =\frac{2}{a^{2 p+1}} L_{p, q-r, r} \\
& \text { ここに } \quad s^{2} u_{1}=a^{2} /\left(a^{2}+\xi_{3}\right)
\end{aligned}
$$

ここにヤコビのだ円関数 $u$ は下式で表されている.

$$
\begin{gathered}
u=\int_{0}^{w} \frac{d t}{\sqrt{1-t^{2}}\left(1-k^{2} t^{2}\right)} \\
\text { ここで, } \quad \begin{array}{c}
w=s n u \\
k^{2}=\left(a^{2}-a^{2}\right) / a^{2}=0
\end{array}
\end{gathered}
$$

円形き裂の場合には, $k=0$ なので, ヤコビのだ円関数 に関しては下に示されている関係式を容易に導くこ とができる.

$$
\begin{aligned}
& w=s n u=\sin u, \quad d n u=\sqrt{1-k^{2} s^{2} u}=1, \\
& n d u=\frac{1}{d n u}=1, \quad c n u=\sqrt{1-\operatorname{sn}^{2} u}=\cos u, \\
& n c u=\frac{1}{c n u}=\frac{1}{\cos u}
\end{aligned}
$$

また, 式(26)に含まれた $L_{p, q-r, r}$ に対しては, 上の関係式 を用いてさらに部分積分により, 次のように整理することが できる.

$$
\begin{gathered}
L_{p, q-r, r}=\int_{0}^{u_{1}}\left(s n^{2 p} u\right)\left(n d^{2 q-2 r} u\right)\left(n c^{2 r} u\right) d u \\
=\int_{0}^{u_{1}}\left(\sin ^{2 p} u\right)\left(\cos ^{-2 r} u\right) d u \\
=\frac{1}{2 r-1}\left[\left.\sin ^{2 p+1} u \cos ^{-2 r+1} u\right|_{0} ^{u_{1}}+2(r-p-1) L_{p, q-r, r-1}\right]
\end{gathered}
$$

したがって, 任意のパラメー夕に対して $L_{p, q-r, r}$ はそれより次 数の低い $L_{p, q-r, r-1}$ と上記の漸化式により次々に求めること ができる. 初期值として必要な最低次の積分は

$$
\begin{aligned}
L_{p, q-r,-1} & =\int_{0}^{u_{1}}\left(\sin ^{2 p} u\right)\left(\cos ^{2} u\right) d u \\
& =\int_{0}^{u_{1}}\left(\sin ^{2 p} u-\sin ^{2 p+2} u\right) d u=I_{p}-I_{p+1} \\
I_{p}= & \int_{0}^{u_{1}} \sin ^{2 p} u d u \\
= & \frac{1}{2 p}\left[-\left.\sin ^{2 p-1} u \cos u\right|_{0} ^{u_{1}}+(2 p-1) I_{p-1}\right]
\end{aligned}
$$

漸化式(32)に用いる初期值は

$$
I_{0}=\int_{0}^{u_{1}} d u=u_{1}
$$

円形き裂においては, 式(27)により

$$
u_{1}=\sin ^{-1} \frac{a}{\sqrt{a^{2}+\xi_{3}}}
$$

となる.

したがって，上記の手順を用いて，任意のパラメー タについてだ円積分の閉じた形の式を求めることが可 能である.

特にき裂面上 $\left(\xi_{3}=0\right)$ における $L_{p, q-r, r}$ についての計 算は次の式で簡単に行われる。

$$
\begin{gathered}
L_{0, q, r-1}=\pi / 4 ;(p=0) \\
L_{p, q, r-1}=\frac{\pi}{4(p+1)} \frac{(2 p-1) ! !}{2 p ! !} \quad ;(p>0) \\
こ こ て ゙,(2 p-1) ! !=(2 p-1) \cdot(2 p-3) \cdot \ldots \cdot 1 \\
2 p ! !=2 p \cdot(2 p-2) \cdot \ldots \cdot 2
\end{gathered}
$$

を意味する。

\section{3 円形き翌緑での応力拡大保数}

与えられた荷重に対して係数 $\{A\}$ が決まり，式 (17)または式(18)を解くことにより係数 $\{C\}$ を決定す ることができる. そこで, 各モードの応力拡大係数 $K_{\mathrm{I}}, K_{\mathrm{n}}, K_{\mathrm{II}}$ は倸数 $\{C\}$ を用いて次のように表される.

$$
\begin{gathered}
K_{\mathrm{I}}=8 \mu \sqrt{\pi} a^{-5 / 2} H_{3} \\
K_{\mathrm{II}}=8 \mu \sqrt{\pi} a^{-5 / 2}\left[H_{1} \cos \theta+H_{2} \sin \theta\right]
\end{gathered}
$$




$$
\begin{gathered}
K_{\mathrm{II}}=8 \mu(1-v) \sqrt{\pi} a^{-5 / 2}\left[H_{2} \cos \theta-H_{1} \sin \theta\right] \\
H_{\alpha}=\sum_{i=0}^{1} \sum_{j=0}^{1} \sum_{k=0}^{m} \sum_{l=0}^{k}(-2)^{2 k+i+j}(2 k+i+j+1) ! \\
\cdot\left(\frac{\cos \theta}{a}\right)^{2 k-2 l+i}\left(\frac{\sin \theta}{a}\right)^{2 l+j} \cdot C_{\alpha, k-l, l}^{(i, j)} \\
(\alpha=1,2,3)
\end{gathered}
$$

ここに, $\theta$ は $x_{1}$ 軸より測られた角度である. これら の手順によって, き裂緣における応力拡大係数が求め られる.

\section{3. 低次荷重における単数円形き翌の解 析}

2 章で示した解析解の正当性を見るために，あらか じめ解析解の分かっている次のような問題を取り上げ た. 無限体中単数円形き裂が次数の低い多項式で表さ れる引っ張り, せん断, 曲げ及びねじり荷重分布を受 ける場合について考える. このとき， $x_{3}=0$ 平面で 考える. この章の最後において, 直線的に変化するせ ん断荷重を受ける円形き裂問題に対する解析を示す.

\section{1 一定引っ張り荷重を受ける堨合}

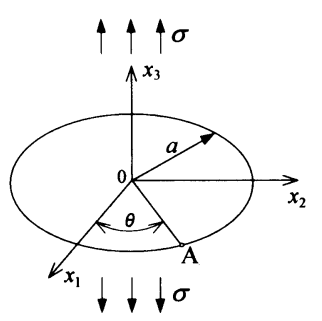

Fig 3 Apennyshapedcrack under uniform tension

まず, 図 3 に示されるように, $\sigma_{33}^{(0)}=\sigma$ の一様な荷 重を受ける場合を考える. 式(14)より係数 $\{A\}$ の值は

$$
A_{3,0,0}^{(0,0)}=\sigma
$$

次に, 式(26)〜 (36)の評価方法に従って以下の関係を 導いた.

$$
J_{1,0,0}(0)=J_{0,1,0}(0)=\frac{\pi}{2 a^{3}}
$$

式(19)の係数 $\{A\}$ と倸数 $\{C\}$ の関係より

$$
\begin{aligned}
A_{3,0,0}^{(0,0)} & =4 \mu\left\{J_{1,0,0}(0)+J_{0,1,0}(0)\right\} C_{3,0,0}^{(0,0)} \\
& =\sigma
\end{aligned}
$$

上式を倸数 $\{C\}$ について解く.

$$
C_{3,0,0}^{(0,0)}=\frac{a^{3}}{4 \mu \pi} \sigma
$$

また，式(37)，(40)によって応力拡大係数は係数 $\{C\}$ を用いて表すと

$$
K_{\mathrm{I}}=8 \mu \sqrt{\pi} a^{-5 / 2} C_{3,0,0}^{(0,0)}
$$

式(44)を上式に代入すると次式が得られる.

$$
K_{\mathrm{I}}=\frac{2}{\pi} \sigma \sqrt{\pi a}
$$

また, き裂面上にせん断荷重が作用していないので, 式 (13), (20)より, $A_{1,0,0}^{(0,0)}=A_{2,0,0}^{(0,0)}=0 ; C_{1,0,0}^{(0,0)}=0 ; C_{2,0,0}^{(0,0)}=0$ となる. 次に, 式(40)より, $H_{1}=H_{2}=0$ となることが求めら れ, 式(38), (39)より

$$
K_{\text {II }}=K_{\text {II }}=0
$$

を求めることができる.

上記の各モードの応力拡大係数は Sneddon ${ }^{(8)}$ にるる解析 解と完全に一致する.

\section{2 一定せん断荷重を受ける場合}

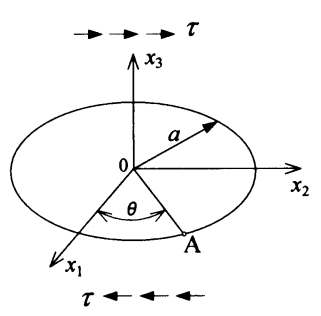

Fig 4 Apennyshaped crack under uniform shear

次に, 図4に示すように $\sigma_{32}^{(0)}=\tau$ の一様なせん断 荷重を受ける場合を考える. 式(13)より係数 $\{A\}$ の值 は

$$
A_{2,0,0}^{(0,0)}=\tau
$$

式(20)の係数 $\{A\}$ と保数 $\{C\}$ の関係より,

$$
\begin{aligned}
A_{2,0,0}^{(0,0)} & =4 \mu\left\{(1-v) J_{1,0,0}(0)+J_{0,1,0}(0)\right\} C_{2,0,0}^{(0,0)} \\
& =\tau
\end{aligned}
$$

上式を係数 $\{C\}$ について解く.

$$
C_{2,0,0}^{(0,0)}=\frac{a^{3} \tau}{2(2-v) \mu \pi}
$$

また, 応力拡大係数は係数 $\{C\}$ を用いて表すと次式と なる.

$$
K_{\mathrm{II}}=8 \mu \sqrt{\pi} a^{-5 / 2} C_{2,0,0}^{(0,0)} \sin \theta
$$




$$
K_{\mathrm{II}}=8 \mu(1-v) \sqrt{\pi} a^{-5 / 2} C_{2,0,0}^{(0,0)} \cos \theta
$$

式(50)を上式に代入し，また式(40)より， $H_{1}=0$ と なるので, 応力拡大係数が求めることができる. その 結果を次式に示す.

$$
\begin{gathered}
K_{\mathrm{I}}=0 \\
K_{\text {II }}=\frac{4 \tau \sqrt{a} \sin \theta}{(2-v) \sqrt{\pi}} \\
K_{\text {II }}=\frac{4 \tau \sqrt{a}(1-v) \cos \theta}{(2-v) \sqrt{\pi}}
\end{gathered}
$$

これらの円形き裂一般解を用いて求められたき裂縁に おける応力拡大係数は $\mathrm{Kassir} \cdot \mathrm{Sih}^{(9)}$ と一致することを確 認した.

\section{3 曲げモーメントを受ける坦合}

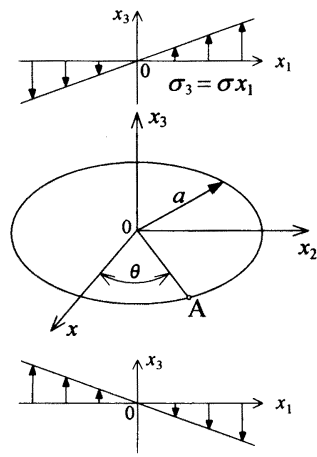

Fig 5 A penny-shaped crack under uniform bending

次に, 図 5 に示すように, $\sigma_{33}^{(0)}=\sigma x_{1}$ のような曲 げ荷重を受ける場合について解析する.

式(13)により係数 $\{A\}$ の值は

$$
A_{3,0,0}^{(1,0)}=\sigma
$$

式(19)の係数 $\{A\}$ と係数 $\{C\}$ の関係によって

$$
\begin{aligned}
A_{3,0,0}^{(1,0)} & =-2 \mu\left[24 J_{2,0,0}(0)+8 J_{1,1,0}(0)\right] C_{3,0,0}^{(1,0)} \\
& =\sigma
\end{aligned}
$$

次に, 式(26)〜 (36)により, 以下の結果を求めた.

$$
J_{2,0,0}(0)=J_{1,1,0}(0)=\frac{3 \pi}{8 a^{5}}
$$

上式を式(57)に代入して係数 $\{C\}$ について解ける. また，応力拡大係数は係数 $\{C\}$ を用いて表すと次式と なる.

$$
K_{\mathrm{I}}=-32 \mu \sqrt{\pi} a^{-7 / 2} \cos \theta \cdot C_{3,0,0}^{(1,0)}
$$

結果として, 次の式が得られる.

$$
K_{\mathrm{I}}=\frac{4 \sqrt{\pi a^{3}}}{3 \pi} \sigma \cos \theta
$$

また, き裂面上にせん断荷重が作用していないので, 式 (13), (20)より, $A_{1,0,0}^{(0,0)}=A_{2,0,0}^{(0,0)}=0 ; C_{1,0,0}^{(0,0)}=0 ; C_{2,0,0}^{(0,0)}=0$ となり, さらに, 式(40)より, $H_{1}=H_{2}=0$ となることが求めら れ, 式(38), (39)より

$$
K_{\text {II }}=K_{\text {III }}=0
$$

を求めることができる.

図 5 の問題に対する Shibuya ${ }^{(10)}$ の解を以下に示す.

$$
K_{\mathrm{I}}=\frac{4 \sqrt{\pi}}{3 \pi} k_{y} R^{3 / 2} \sin \theta^{\prime}
$$

上式の $k_{y}, R, \theta^{\prime}$ は本論文で使用している $\sigma, a, \theta$ と以 下の関係をもつ.

$$
\begin{gathered}
k_{y}=\sigma \\
R=a \\
\theta^{\prime}=\theta+\pi / 2
\end{gathered}
$$

これらの関係式を式(62)に代入することにより, 円 形き裂の一般解を用いて求めた応力拡大係数の值, 式 (60) (61)は Shibuya ${ }^{(10)}$ の解と一致することが分かる.

\section{4 ねじりを受ける封合}

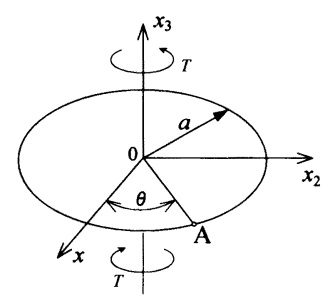

Fig 6 Apennyshapedcrack under torsional bading

次に, 図6に示すように円形き裂はねじりモ一メン ト $T\left(T=\pi \tau a^{3} / 2\right)$ のせん断荷重を受けるときについ て述べる. 座標変換により $\sigma_{31}^{(0)}=-(\tau / a) x_{2}$, $\sigma_{32}^{(0)}=(\tau / a) x_{1}$ の関係式が得られる. 式(13)より係数 $\{A\}$ を記述して次式を得ることができる.

$$
\sigma_{31}^{(0)}=A_{1,0,0}^{(0,1)} x_{2}, \quad \sigma_{32}^{(0)}=A_{2,0,0}^{(1,0)} x_{1}
$$

係数 $\{A\},\{C\}$ の関係式より, 次式が求まる.

$$
\begin{aligned}
A_{1,0,0}^{(0,1)} & =-2 \mu\left\{\left[8 J_{1,1,0}(0)+24(1-v) J_{0,2,0}(0)\right] C_{1,0,0}^{(0,1)}+8 v J_{1,1,0}(0) C_{2,0,0}^{(1,0)}\right\} \\
& =-\tau / a
\end{aligned}
$$




$$
\begin{aligned}
A_{2,0,0}^{(1,0)} & =-2 \mu\left\{\left[8 J_{1,1,0}(0)+24(1-v) J_{2,0,0}(0)\right] C_{2,0,0}^{(1,0)}+8 v J_{1,1,0}(0) C_{1,0,0}^{(0,1)}\right\} \\
& =\tau / a
\end{aligned}
$$

以上の連立方程式で解いた係数 $\{C\}$ を式(37)〜 (40)に 代入して応力拡大係数が求められる.

$$
\begin{aligned}
K_{\mathrm{I}}= & 2 \tau \sqrt{\pi} a^{-9 / 2} \frac{\sin \theta \cos \theta}{\Delta}\left\{(1+v)\left[J_{1,1,0}(0)-J_{1,1,0}(0)\right]\right. \\
& \left.+3(1-v)\left[J_{0,2,0}(0)-J_{0,2,0}(0)\right]\right\}=0
\end{aligned}
$$

$$
\begin{aligned}
K_{\mathrm{II}} & =2(1-v) \tau \sqrt{\pi} a^{-9,2} \frac{(1+v) J_{1,1,0}+3(1-v) J_{0,2,0}}{\Delta} \\
& =\frac{4 \tau}{3} \sqrt{\frac{a}{\pi}}=\frac{8 T}{3 \pi^{3 / 2} a^{5 / 2}}
\end{aligned}
$$

$$
\Delta=(1-v)\left\{(1+v)\left[J_{1,1,0}(0)\right]^{2}+3\left[J_{1,1,0}(0) J_{0,2,0}(0)\right.\right.
$$$$
\left.\left.+J_{1,1,0}(0) J_{2,0,0}(0)\right]+9(1-v) J_{0,2,0}(0) J_{2,0,0}(0)\right\}
$$

ここに

$$
J_{0,2,0}(0)=J_{1,1,0}(0)=J_{2,0,0}(0)=\frac{3 \pi}{8 a^{5}}
$$

き裂面上に垂直荷重が作用していないので, 式(13)， (19)より, $A_{3,0,0}^{(0,0)}=0 ; C_{3,0,0}^{(0,0)}=0$ となる. 式(40)より, $\mathrm{H}_{3}=0$ であることが求められ, また, 式(37)より, $K_{1}=0$ となる.

上記の応力拡大倸数は Kassir·Sir ${ }^{(1)}$ の解と完全に一致 する.

以上のように挙げた例題に求められた応力拡大係数 の值は文献 とも完全に一致する。このことから，混 合モード条件下の無限体中の円形き裂問題の解析解を 2 章に示した一般解より, 容易にしかも正しく求めら れることが確認できた.

\section{5 直線的に変化するせん断荷重を受け る堨合}

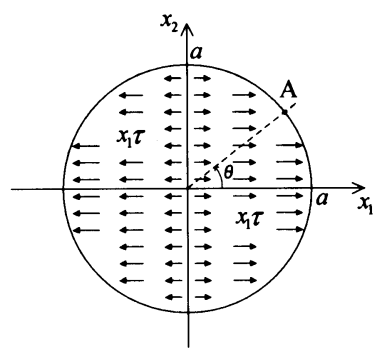

Fig 7 Apennyshaped crack under symmetric shear bading
最後に，円形き裂の一般解の有効性を示すため, 図 7 に示すように, $\sigma_{31}^{(0)}=x_{1} \tau$ の $x_{1}$ 方向にせん断荷重が 直線的に変化する場合を考える.

式(13)により係数 $\{A\}$ の值は

$$
A_{1,0,0}^{(1,0)}=\tau
$$

となる. 式(19)の倸数 $\{A\}$ と倸数 $\{C\}$ の関倸により,

$$
A_{1,0,0}^{(1,0)}=-2 \mu\left[I_{1}^{(1,0)} J_{2,0,0}(0)+(1-v) I_{2}^{(1,0)} J_{1,1,0}(0)\right] C_{1,0,0}^{(1,0)}
$$

また, 式(26)〜 (36)により, 以下の結果を求める.

$$
\begin{aligned}
& I_{1}^{(1,0)}=24, I_{2}^{(1,0)}=8 \\
& J_{2,0,0}(0)=J_{1,1,0}(0)=3 \pi /\left(8 a^{5}\right)
\end{aligned}
$$

式(70), (72), (73)を式(71)に代入して係数 $\{C\}$ を求める ことができる.

$$
C_{1,0,0}^{(1,0)}=-\frac{a^{5}}{6 \mu \pi(4-v)} \tau
$$

上式を式(37)〜(40)に代入して各モードの応力拡大係 数は次式となる.

$$
\begin{gathered}
K_{\mathrm{I}}=0 \\
K_{\text {II }}=\frac{16 \tau \sqrt{a^{3}} \cos ^{2} \theta}{3(4-v) \sqrt{\pi}} \\
K_{\text {II }}=\frac{-8 \tau \sqrt{a^{3}}(1-v) \sin 2 \theta}{3(4-v) \sqrt{\pi}}
\end{gathered}
$$

この節に示した円形き裂問題から，式（13）で表さ れる荷重における係数 $\{A\}$ を見付けられれば，2章に 示している円形き裂の一般解の解析手順に従って, 容 易に円形き裂の応力拡大倸数を導くことができること がわかる.

\section{4. 任意の荷重における応力拡大係数}

開発したプログラムにおいては，任意のき裂面にか かる荷重分布に対して，あらかじめき裂面に設置した 均整の取れた 709 個の補間点における応力成分を算出 し, 最小二乗法を用いて式(13)の多項式の保数 $\{A\}$ を 決定する数值解析手法を取り入れる.

ここでは，円形き裂がき裂面上に次のような垂直荷 重を受ける場合を考える. 


$$
\begin{aligned}
& \sigma_{33}^{(0)}=-P_{0} x_{1}^{2}+P_{0} x_{2}^{2} \\
& \sigma_{33}^{(0)}=-3 P_{0} x_{1}^{2} x_{2}+P_{0} x_{2}^{3}
\end{aligned}
$$

これらの問題においての応力拡大係数の Shah・

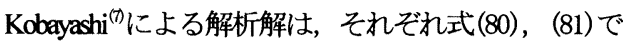
ある.

$$
\begin{aligned}
& K_{\mathrm{I}}=16 P_{0} \cos \theta /(15 \sqrt{\pi}) \\
& K_{\mathrm{I}}=32 P_{0} \sin 3 \theta /(35 \sqrt{\pi})
\end{aligned}
$$

図8に解析結果としての円形き裂縁におけるモード I の応力拡大係数を示す. Oは本方法による円形き裂 の数值解析解である. 図より両者の結果は完全に一致 することが分かる. 本論文に示した円形き裂の一般解 とその数值計算プログラムが正確であることが分かっ

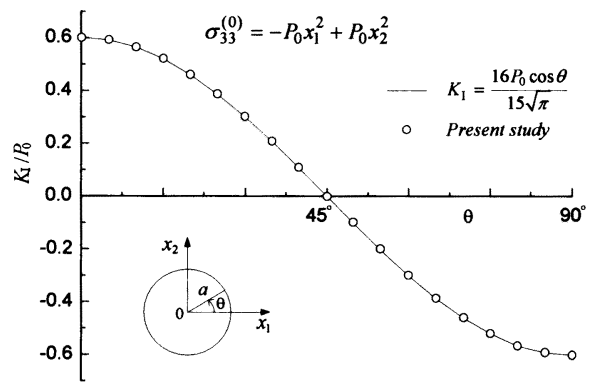

(a) A penny-shaped crack under secondary loading

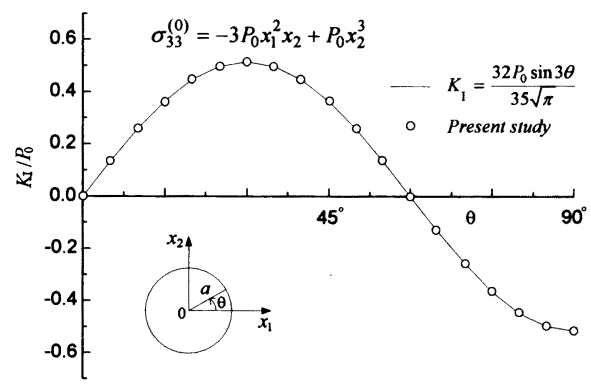

(b) A penny-shaped crack under cubic loading

Fig 8 Stress intensity factor for a circularcrack in an infinite solid and subjected to pressure
た.

\section{5. 結言}

本論文では無限体中の円形き裂の一般解の完全な形 を導くことに成功した. そして，この円形き裂の一般 解の正確性を検証するため, 各低次（引つ張り, せん 断，曲げおよびねじり）荷重条件に対して文献(た完 全に一致した閉じた解を導くことができ，また， 2 次 および 3 次垂直荷重における円形き裂縁の応力拡大係 数の数值計算を行った.

この円形き裂一般解の導出することにより，任意の 次数の多項式で表される荷重条件における円形き裂に ついての数值計算ができることを示した.

\section{謝辞 :}

この研究において, 本研究室特別研究員の周志東氏 に助言を得た。

\section{考文献}

(1) Vijyakumer, K \& Athri, S N : An Embedded Elipticalcrack, in an infinite Sotid, Subject toArtitrany Crack Fane Tractions, J.Appl Mech 48(1981), 8896.

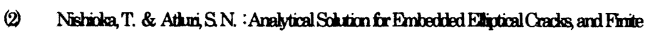
Element Allemeting Method for Eliptical Surface Cradks, Subjected to Artitrany Loadings Fing Fract Mech 17(1983), 247-268

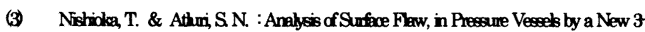
Dimensinal Altemeting Method, Trans ASME, J. Pres Veed Tectnd , 1044 (1962), 299307.

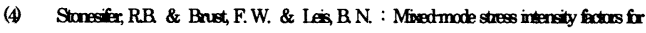
interactingSemielipticalSunfaeCrackinaphte, Eng Fract Mech 45, (1998), 357-380

(5) Byrd, R. F. \& Fiodman, M. D. : Handbook of Whiptic Integrals frr Engimeers and Scientiots, SpringerVetag Berin, (1971).

(6) Stressintensity factushandbook, Vd2, Peqamon Pros (1990, 60801

(7) Shah R C. \& Kobeyashi, A S : Stress Intensity Factar for an Fliptical Crack under Artitrany Nomal Loeding Eng Fract Mech, $3(1971), 7196$

(8) Sheddon I N : The Distribution of Stress in the Nethounhood of a Crack in an Elestic Solid, Proc Boy. London, Ser. A Vd187, (1946).

(9) Kassir, M. K \& Sin G. C: TheeDimensional Stres Distobution Around an Eliptical Crack Under Artitrary Loadings Trans ASME, Ser.E, J.Appl Mach, Vd33 (1966), 601 611

(10) Shibuya T. : SameMined Boundary ValueProblemsfran InfiniteSolid Containinga Flat

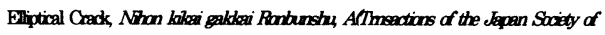
Mectrical Engineers Stivis $A$ ), 42364(1976), 37183725

(11) Karsir, M. K \& Sir, G. C. : Mechaniss of Fractume2, Thee-Dimensinal Crack Problems Nocrdhoflntemetional Publishing Leyden (1975), 2524.

(12) C.M. Segedin : Report 67-3, Depertment of Aeronautios and Actronatios, Univ. of Washington, Jume 1967. 